\title{
Riqueza y abundancia de aves insectívoras de sotobosque en tres sitios con diferente grado de disturbio forestal
}

\author{
Paul E. Oviedo Pérez \\ Profesor de la Catedra Ecología y Educación Ambiental, Escuela Ciencias Exactas y Naturales, Universidad Estatal a \\ Distancia; poviedop@uned.ac.cr
}

Recibido: 26 junio 2017

RESUMEN

La riqueza y abundancia de aves insectívoras de sotobosque fue estimada en tres hábitats con diferente grado de disturbio forestal, usando estaciones permanentes y redes de niebla como método de muestreo. Se capturaron 191 individuos pertenecientes a 28 especies. La riqueza y abundancia relativa media fueron comparadas con pruebas de análisis de varianza. Hubo una tendencia hacia una mayor riqueza y abundancia de aves insectívoras en el borde del bosque y durante la estación seca. La mayoría de las especies capturadas fueron consideradas como raras. Especies de matorrales fueron capturadas dentro del bosque maduro y especies propias de bosques densos aún persisten en el hábitat con mayor disturbio. Tanto la conectividad como la variedad de ambientes en diferente estado de regeneración permiten una alta tasa de recambio y son importantes para la conservación de las aves insectívoras.

Palabras claves: abundancia, aves insectívoras, riqueza, sotobosque.

\begin{abstract}
Richness and abundance of understory insectivorous birds was estimated in three habitats with different degrees of forest disturbance, using permanent stations and mist nets as sampling method. I captured 191 individuals belonging to 28 species. The relative richness and abundance were compared with tests of variance analyzes. There was a trend towards greater richness and abundance of insectivorous birds at the edge of the forest and during the dry season. Most of the captured species were considered rare. Scrub species were captured within the mature forest and mature forest species still persist in highly altered habitats. Both the connectivity and the variety of environments in different regeneration conditions allow a high turnover rate and are important for the conservation of insectivorous birds.
\end{abstract}

Key words: abundance, insectivorous birds, richness, understory.
Aceptado: 20 octubre 2017

\section{Introducción}

La ganadería, la agricultura y la urbanización modifican la cobertura vegetal de los bosques tropicales. Muchas de las especies de aves que habitan el sotobosque de estos ecosistemas son en su mayoría soterreyes (Troglodytidae), trepatroncos (Dendrocolaptidae) y batarás (Thamnophilidae). Estas aves son por lo general de hábitos muy sedentarios; es decir, no sostienen el vuelo por largas distancias. La principal fuente de alimento de estas aves son los insectos y otros artrópodos, por lo que han desarrollado comportamientos altamente especializados en evitar la depredación mientras se alimentan de presas muy específicas (Kricher, 1997; Moore, Robinson, Lovette y Robinson, 2008). El recurso alimenticio de las aves insectívoras disminuye considerablemente durante la época seca, aún en bosques poco perturbados (Verea y Solórzano, 1998). Sin embargo, otros estudios sugieren que algunas aves insectívoras tienen plasticidad fenotípica para aclimatarse, adaptarse y tolerar los cambios en las condiciones ambientales; así como, aquellos provocados por la actividad humana (Andrade y Rubio-Torgler, 1994; Castro, Valladares y Alonso, 2004). Por lo tanto, la vulnerabilidad de las aves insectívoras a los cambios provocados en su hábitat todavía debe ser evaluada (Stouffer, Bierregard, Strong y Lovejoy, 2006; Stouffer y Bierregaard, 2007).

Estudios previos indican que los disturbios en la fisonomía del bosque tropical provocan pérdida de hábitat, disminución en la abundancia y hasta la extinción de algunas especies dentro de este gremio de aves (Stouffer y Bierregard, 
1995; Sodhi, Liow y Bazzaz, 2004). La calidad del hábitat y su grado de heterogeneidad influyen considerablemente en la presencia o ausencia de aves insectívoras de sotobosque en un lugar determinado (Sánchez, 2011). Los atributos de hábitat también afectan la eficiencia de forrajeo y el éxito reproductivo de las aves (Zanette, Doyle y Tremont, 2000; Stratford y Stouffer, 2001). A escala de paisaje, la conectividad por medio de los fragmentos de bosque es una variable importante, que facilita o impide que los individuos puedan desplazarse con libertad entre los hábitats (Bennett, 2004).

Los efectos de la alteración del hábitat sobre las comunidades de aves tropicales han sido estudiados en Latinoamérica desde los años ochenta (Rappole y Morton, 1985; Lovejoy et al. 1986; McCoy y Mushinsky, 1994). En Costa Rica este tipo de estudios tuvo mucho interés en la comunidad científica en la década de los noventas (Young, 1999). La mayoría de las investigaciones fueron realizadas en los bosques húmedos tropicales de la Vertiente del Caribe (Sánchez, 2011), en partes altas de las cordilleras (Young, Derosier y Powell, 1998) y en el Pacífico Sur (Sekercioglu, Loarie, Oviedo, Ehrlich y Daily, 2007). No obstante, en los bosques húmedos de la Península de Nicoya este tipo de investigaciones son escasas. Los inventarios de aves en esta península son frecuentes, pero son pocos los estudios demográficos. Todavía existen vacíos de información sobre la dinámica de las poblaciones y los impactos de la deforestación sobre la avifauna de los bosques húmedos del Pacífico Norte de Costa Rica (Villarreal, 2005). El objetivo de este estudio fue estimar la riqueza y la abundancia de aves insectívoras residentes de sotobosque en tres sitios con diferente grado de disturbio forestal al suroeste del Pacífico Norte de Costa Rica, afín de identificar aquellas especies que todavía persisten en los hábitats más alterados por las actividades humanas y que requieren un mayor esfuerzo de conservación.

\section{Materiales y métodos}

Sitio de estudio. Esta investigación fue realizada en la zona comprendida entre la Reserva
Natural Absoluta Cabo Blanco (RNA) y la desembocadura del río Lajas en Cabuya, al suroeste de la Península de Nicoya (9 $33^{\circ}$ y $9^{\circ} 36^{\prime} \mathrm{N}$ $85^{\circ} 05^{\prime}$ y $85^{\circ} 09^{\prime} \mathrm{W}$ ), provincia de Puntarenas. La zona de vida corresponde a bosque húmedo premontano transición a basal (bmh-P). La precipitación anual oscila entre 2500 y $3200 \mathrm{~mm}$ lluvia. La temperatura anual media es de $27^{\circ} \mathrm{C}$. La humedad relativa anual media es de $81 \%$ (Jiménez, 2013).

Tres hábitats con diferente grado de disturbio forestal fueron seleccionados: interior de bosque, borde de bosque y bosque ribereño. El interior de bosque está localizado en el centro de la RNA Cabo Blanco y ha permanecido cerrado al tráfico de turistas por más de 30 años. El borde de bosque consta de la franja de vegetación ubicada a lo largo del límite noreste de la RNA Cabo Blanco, tiene alto tráfico de turistas, senderos, caminos y albergue para guardaparques. El bosque ribereño consiste en la vegetación que crece a orillas de riachuelos y quebradas que recorren el pueblo de Cabuya. Este tercer hábitat está dentro de fincas ganaderas y combina charrales, matorrales con árboles de rápido crecimiento y bosque secundario (Oviedo, 2015).

Muestreo de aves insectívoras. El presente estudio fue realizado de febrero a abril (época seca) y de junio a agosto (época lluviosa) del 2015. En cada uno de los hábitats seleccionados se establecieron cinco estaciones de muestreo con una distancia mínima de $200 \mathrm{~m}$ entre sí. Tres redes de niebla $(2,5 \mathrm{~m}$ de altura, $12 \mathrm{~m}$ de longitud de malla de $32 \mathrm{~mm}$ ) fueron colocadas en cada estación. La distancia mínima entre redes fue de $25 \mathrm{~m}$. Sólo fue muestreado un hábitat por día, las redes fueron rotadas entre los hábitats a lo largo del período de estudio. Cada estación fue muestreada una vez en cada época (seca-lluviosa). Las redes estuvieron abiertas desde el ras del suelo hasta una altura de $2 \mathrm{~m}$. La captura de aves fue realizada de 07:00 a 11:00 a.m. y entre 15:00 a 17:00 p.m. El esfuerzo total de captura de aves fue de $540 \mathrm{hr} / \mathrm{red}(180 \mathrm{hr} / \mathrm{red}$ en cada hábitat).

Para efecto de este estudio se designaron como aves insectívoras a todas las especies que 
se alimentan principalmente de artrópodos y que pueden o no complementar su dieta con frutos, utilizando como referencia la dieta documentada por Stiles y Skutch (2007). A cada ave capturada se le colocó un anillo de celulosa enumerado para su reconocimiento y evitar el recuento durante un mismo día de muestreo. Las aves fueron identificadas a nivel de especie. Las recapturas realizadas en un mismo día de muestreo fueron excluidas de todos los análisis (Stouffer y Bierregaard, 1995); así como, las especies insectívoras neárticas.

Estimación de riqueza y abundancia. $\mathrm{Se}$ anotó tanto el número de especies como de individuos por especie capturados en cada red. Se utilizó la tasa de captura (aves/hr/red) como un índice estándar de riqueza y abundancia. Se comparó la riqueza de especies y abundancia entre los tres hábitat usando pruebas de ANOVA de dos factores, usando como primer factor el hábitat y como segundo factor la época del año (seca
- lluviosa). Estas comparaciones fueron realizadas con el programa STATGRAPHICS Centurion XV 2006, siguiendo los supuestos de normalidad y homocedasticidad (Sokal y Rohlf, 2012).

\section{Resultados}

Se capturaron 191 aves insectívoras residentes de sotobosque, pertenecientes a 28 especies. Las especies más abundantes fueron Dendrocincla homochroa, Glyphorhynchus spirurus, Thamnophilus doliatus y Cantorchilus rufalbus. Los mosqueros americanos (Tyrannidae) fue la familia mejor representada con 10 especies, seguida por la familia Troglodytidae y Dendrocolaptidae, con cinco y cuatro especies, respectivamente. Después de 250 horas de captura no se registraron nuevas especies en ninguno de los tres hábitats (Fig. 1).

En general, tanto la riqueza total de especies como la tasa de captura fueron más altas en el interior del bosque (Tabla 1). La riqueza total en

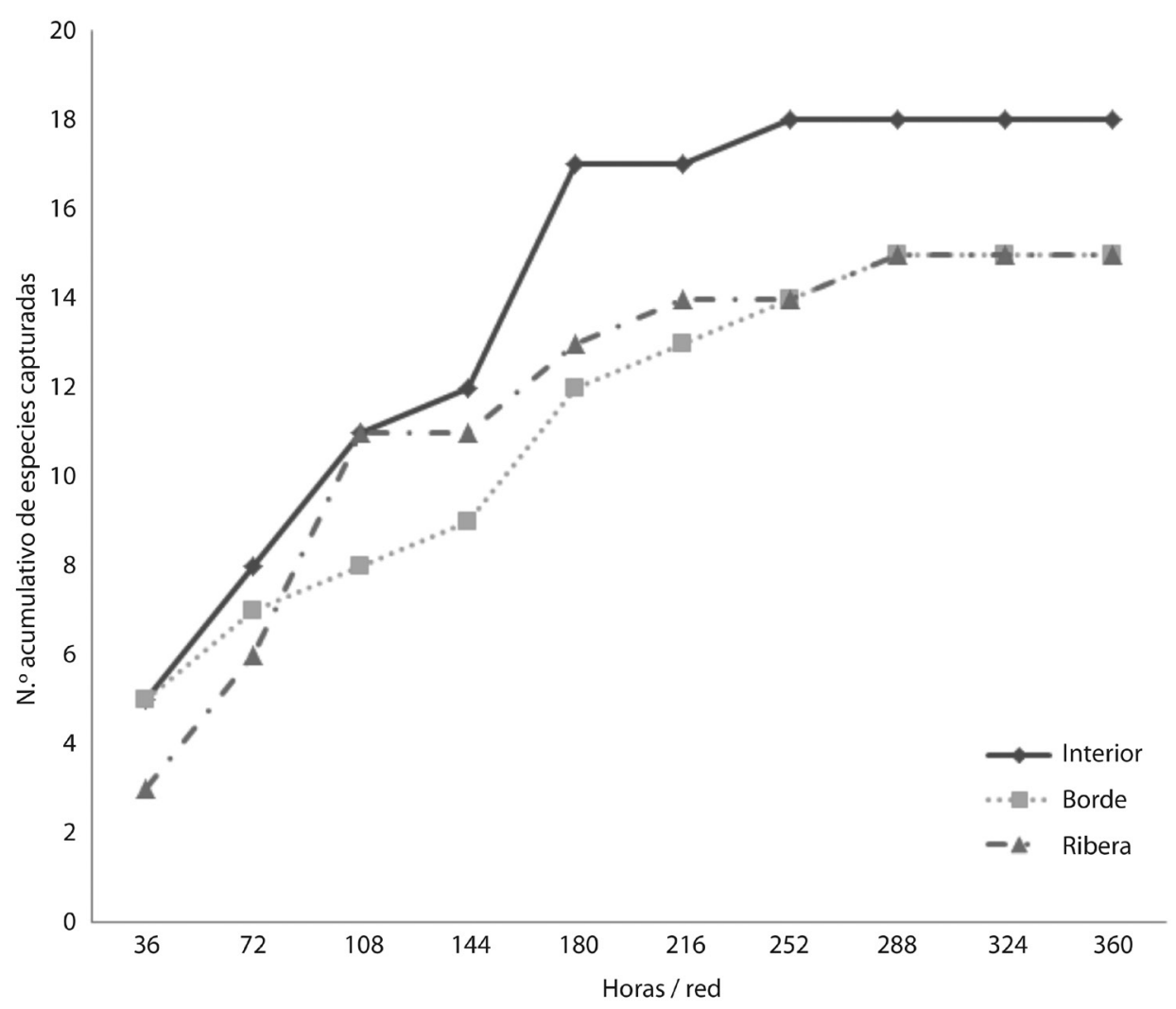

Figura 1. Curva de acumulación de especies de aves insectívoras de sotobosque en tres hábitat (interior de bosque, borde bosque y bosque ribereño) al suroeste del Pacífico Norte, Costa Rica, 2015. 
TABLA 1

\section{Riqueza y abundancia de aves insectívoras de sotobosque en tres sitios con diferente grado de} disturbio forestal, suroeste de la Península de Nicoya, Costa Rica, 2015

\begin{tabular}{lccc}
\multicolumn{1}{c}{ Variable } & Hábitat & \\
Riqueza total & Interior de bosque & Borde de bosque & Bosque ribereño \\
Especies de interior de bosque & 18 & 15 & 15 \\
Especies raras (\%) & 13 & 10 & 4 \\
Abundancia total & 72 & 67 & 73 \\
Tasa media de captura (aves/hr/red) & 64 & 74 & 53 \\
Recapturas & $0,5 \pm 0,08$ & $0,4 \pm 0,08$ & $0,3 \pm 0,08$ \\
\hline
\end{tabular}

el interior del bosque fue de 18 especies, de las cuales Dendrocincla homochroa, Xiphorhynchus flavigaster y Platyrinchus cancrominus, están catalogadas como especies propias de bosques maduros (Stiles y Skutch, 2007). Un 27,8\% de las especies registradas en el interior de bosque no son consideradas propias de ese tipo de hábitat, ya que también frecuentan bosques secundarios y matorrales, por ejemplo: Myiarchus tuberculifer y Canthorchilus modestus (Stotz, Fitzpatrick, Parker y Moskovit, 1996). En el borde de bosque se registró un $66,7 \%$ de las especies propias de interior de bosque; mientras que en los bosques ribereños solamente un $31,8 \%$ de las especies fueron propias de interior de bosque, tal es el caso de C. rufalbus.

La riqueza relativa media fue mayor en el borde de bosque $(0,28 \pm 0,03)$ en comparación con los otros hábitats, aunque no de forma significativa $\left(\mathrm{F}_{(2,78)}=0,62 ; \mathrm{P}=0,5404\right)$. La riqueza relativa media durante la época seca fue significativamente mayor en comparación con la época lluviosa $\left(\mathrm{F}_{(1,178)}=3,98 ; \mathrm{P}=0,0502\right)$.

Aproximadamente el $70 \%$ de las especies registradas en cada uno de los hábitats fueron raras, con cuatro individuos o menos. Además ninguna de las especies superó los 15 individuos por hábitat, por lo que pueden ser consideradas poco abundantes. El hábitat con más individuos capturados fue el borde de bosque; sin embargo, la tasa media de captura fue mayor en el interior del bosque (Tabla 1), aunque no de manera significativa $(\mathrm{P}>0,05)$. No hubo recapturas en el interior del bosque. Las recapturas en el borde de bosque y bosque ribereño sólo alcanzaron el
$2,7 \%$ y $9,4 \%$ de las capturas totales, respectivamente. La abundancia relativa media durante la época seca $(0,34 \pm 0,031)$ fue significativamente mayor en comparación con la época lluviosa $(0,25 \pm 0,031)\left(\mathrm{F}_{(1,178)}=3,44 ; \mathrm{P}=0,05\right)$.

Las especies de la familia Dendrocolaptidae mostraron una marcada disminución en la abundancia relativa media en relación con el grado de alteración del hábitat, a tal punto que estuvieron casi ausentes o totalmente ausentes en los bosques ribereños de Cabuya. Por el contrario, especies como T. doliatus, C. rufalbus y A. spadiceus, no sólo persisten en hábitat altamente alterados, sino que además fueron menos abundantes en el interior del bosque (Tabla 2).

\section{Discusión}

Los resultados de la riqueza y la abundancia sugieren que existe cierta similitud en la composición de aves insectívoras de sotobosque entre los tres hábitats estudiados. La variación de la riqueza y las abundancias de las aves pueden ser atribuibles al intercambio de especies que ocurre entre los hábitats contiguos de este paisaje heterogéneo. La mayor presencia de aves insectívoras en el borde de bosque, localizado entre los otros dos hábitats, apoya este argumento. También podría haber una mayor cantidad de insectos en el borde de bosque, aunque esa hipótesis deberá ser estudiada en próximas investigaciones. La presencia de especies propias de interior de bosque en hábitats perturbados sugiere que, tanto la conectividad como la variedad de ambientes, son importantes para la conservación 
TABLA 2

Abundancia relativa (media \pm D.E.) de las siete especies de aves insectívoras de sotobosque más abundantes al suroeste de la Península de Nicoya, Costa Rica, 2015

\begin{tabular}{lcccc}
\multicolumn{1}{r}{ Especie } & \multicolumn{3}{c}{ Hábitat } & Ribereño \\
D. homochroa & $0,061 \pm 0,0087$ & Borde & $0,012 \pm 0,0087$ & 0,0002 \\
S. griseicapillus & $0,043 \pm 0,015$ & $0,075 \pm 0,0015$ & $0,006 \pm 0,015$ & 0,0160 \\
X. flavigaster & $0,043 \pm 0,009$ & $0,019 \pm 0,009$ & $0,0062 \pm 0,009$ & 0,0351 \\
T. doliatus & $0,019 \pm 0,032$ & $0,12 \pm 0,032$ & $0,07 \pm 0,032$ & 0,0926 \\
P. cancrominus & $0,043 \pm 0,009$ & $0,012 \pm 0,009$ & $0,006 \pm 0,009$ & 0,0204 \\
A. spadiceus & $0,031 \pm 0,011$ & $0,061 \pm 0,011$ & $0,006 \pm 0,011$ & 0,0047 \\
C. rufalbus & $0,025 \pm 0,022$ & $0,10 \pm 0,022$ & $0,06 \pm 0,022$ & 0,05 \\
\hline
\end{tabular}

de las aves insectívoras. El borde de bosque al tener un grado de regeneración intermedia en comparación con el interior de bosque y los remanentes de bosque ribereño, alberga especies de estos dos hábitats. La dinámica propia de los bordes de bosque ofrece una mayor cantidad de nichos en comparación con los bosques maduros (MacArthur y Wilson, 1967), por lo que es un ambiente en donde convergen especies tanto de zonas abiertas como de bosques maduros. Lo anterior explica la tendencia registrada a un incremento de riqueza y abundancia en el borde de bosque.

La tasa media de captura en los tres sitios coincide con otras registradas para especies insectívoras neotropicales (Naranjo y Chacón, 1997; Sánchez, 2011). La baja tasa de recaptura indica una alta tasa de recambio en la comunidad de aves del sotobosque a lo largo del año. Este recambio puede estar relacionado a cambios fenológicos estacionales, debido a que durante la época seca la mayoría de las especies arbóreas son caducifolias. Por lo tanto, las especies insectívoras de los estratos intermedios son forzadas a forrajear sobre el sotobosque (e.g., A. spadiceus, $S$. griseicapillus); contrario a lo que sucede en la época lluviosa, cuando pueden alimentarse en los estratos superiores del bosque, quedando fuera del alcance de las redes. Asimismo, la menor densidad de cobertura foliar que caracteriza a la época seca, permite que especies comunes de zonas en regeneración (e.g., M. tuberculifer, C. modestus, A. conirostris), puedan aventurarse al interior del bosque.
En conclusión, este estudio sugiere que los hábitats en diferente estado de regeneración dentro del paisaje al suroeste de la Península de Nicoya conservan especies de aves insectívoras propias de bosques húmedos tropicales, las cuales no podrían sobrevivir en potreros o pastizales. Los remanentes de bosque a las orillas de los ríos conservan una porción de la avifauna nativa de bosques densos y maduros. La ausencia de algunas especies de aves en los bosques ribereños de las fincas ganaderas, principalmente trepatroncos (Dendrocolaptidae), sugiere que aves pertenecientes a esa familia pueden ser utilizadas como indicadoras de la calidad del hábitat.

Ante el incremento de proyectos urbanísticos en Cabuya, se recomienda conservar los fragmentos de vegetación y bosques ribereños; así como, aumentar la cobertura arbórea en los potreros. La gente local debe evitar el uso del fuego y la extracción insostenible de madera de los parches y bosques ribereños. Es necesario mantener parches en diferentes estadios de regeneración natural, principalmente a orillas de fuentes de agua, para facilitar una mayor conservación de aves insectívoras.

Próximas investigaciones deben analizar cómo la estructura y composición florística influye sobre cada una de las especies de aves insectívoras. Además, hay que tener en cuenta que los diferentes organismos responden de formas muy distintas a la transformación del paisaje, todo depende de su capacidad de dispersión, del tamaño y la forma de los parches, del grado de 
conectividad y de los requerimientos de hábitat para cada especie.

\section{Agradecimientos}

Esta investigación fue apoyada por Idea Wild, Área de Conservación Tempisque y el Sistema Nacional de Áreas de Conservación. Se agradece la colaboración de Paul Ureña, Natalia Corrales y Andrés Jiménez durante el trabajo de campo.

\section{Referencias}

ANDRADE, G. I. y RUBIO-TORGLER, H. (1994). Sustainable use of the tropical rain forest: evidence from the avifauna in a shifting-cultivation habitat mosaic in the Colombian Amazon. Conservation Biology, 8: 545-554.

BENNETT, A. (2004). Enlazando el paisaje: el papel de los corredores y la conectividad en la conservación de la vida silvestre. UICN. San José, Costa Rica. 276 p.

CASTRO, P., VALLADARES, F y ALONSO, A. (2004). La creciente amenaza de las invasiones biológicas. Ecosistemas, 13(3): 61-68.

IDROBO, C. J. y GALLO, E. (2012). Movilidad de aves de sotobosque entre fragmentos de bosque subandino en los Andes colombianos. Memorias: Manejo de Fauna Silvestre en Amazonia y Latinoamérica. Recuperado de http://www.comfauna.org/wp-content/uploads/2012/PDFs-Manejofaunasilvestre/ Iquitos2004/3_Investigacion_Biologica_ Aplicable_al_Manejo/195202_cidrobo_ MovilidadAvesSotobosqueFragmentosBosque.pdf

JIMÉNEZ, A. 2013. Caracterización de la avifauna terrestre de la Reserva Natural Absoluta Cabo Blanco, sector Cabuya. Puntarenas, Costa Rica. Informe final de Práctica Dirigida para optar por el título de Bachiller en Manejo de Recursos Naturales. Universidad Estatal a Distancia, San José, Costa Rica. 53 p.

KRICHER, J. (1997). A Neotropical Companion: an introduction to the animals, planst \& ecosystem of the new world tropics. Princeton University Press. United kingdom. $451 \mathrm{p}$.

LOVEJOY, T. E., BIERREGAARD, R.O., RYLANDS, B., MALCOM, J. R., QUINTINELA, C. E., HARPER, L. H., BROWN, K. S., POWELL, A. H., POWELL, G.
V. N., SCHUBART H. O. R. y HAYES. M. B. (1986). Edge and other effects of isolation on Amazon forest fragment. In: M. E. SOULÉ (ed). Conservation biology: the science of scarcity and diversity. Sinauer, Sunderland, Massachussets, EE.UU. pp 257-285.

MACARTHUR, R. H. y WILSON, E. O. (1967). The theory of island biogeography. Princeton University Press, Princeton, EE.UU.

MCCOY, E. D. y MUSHINSKY, R. H. (1994). Effects of fragmentation on the richness of vertebrates in the Florida scrub habitat. Ecology, 75: 446-457.

MOORE, R. P., ROBINSON, W. D., LOVETTE, I. J. y ROBINSON, T. R. (2008). Experimental evidence for extreme dispersal limitation in tropical forest birds. Ecology Letters, 11: 960-968.

NARANJO, L. G. y CHACÓN. P. (1997). Diversidad de insectos y aves insectívoras de sotobosque en hábitats perturbados de selva lluviosa tropical. Caldasia, 19(3):507-520.

OVIEDO, P. (2015). Composición y estructura forestal de la Reserva Absoluta de Cabo Blanco y remanentes de bosque del sector de Cabuya, Puntarenas, Costa Rica. Repertorio Científico, 18(2): 95-102.

RAPPOLE, J. H. y MORTON, E. S. (1985). Effects of habitat alteration on a tropical avian forest community. In: P. A. BUCKLEY (ed). Neotropical Ornithology. The American Ornithologists Union. Washington, DC, EE.UU. pp 1013-1020.

SÁNCHEZ, N. V. (2011). Abundancia de tres especies de aves insectívoras de sotobosque y disponibilidad de recursos en bosques tropicales de llanura, Sarapiquí, Costa Rica. Tesis Mag. Sc. Heredia, C.R., ICOMVIS, UNA. 49 p.

SEKERCIOGLU, C., LOARIE, S. R., OVIEDO, F., EHRLICH, P. R. y DAILY, G. C. (2007). Persistence of forest birds in the Costa Rican Agriculture Countryside. Conservation Biology, 21: 482-494.

SODHI, N. S., LIOW, L. H. y. BAZZAZ, F. A. (2004). Avian extinctions from tropical and subtropical forest. Annual Review of Ecology, Evolution and Systematics, 35: 323-345.

SOKAL, R. R. y. ROHLF, F. J. (2012). Biometry: the principles and practice of statistics in biological research. Freeman \& Company, N.Y., EE.UU. 937 p. 
STILES, F. G. y SKUTCH, A. (2007). Guía de aves de Costa Rica. INBio. Heredia, Costa Rica. 571 p.

STOTZ, D., FITZPATRICK, J., PARKER, T. y MOSKOVIT, D. (1996). Neotropical birds: Ecology and Conservation. University of Chicago Press. Chicago, EE.UU. 478 p.

STOUFFER, P.C y BIERREGAARD, R. O. (1995). Use of Amazonian forest fragments by understory insectivorous birds. Ecology, 76(8): 2429-2445.

STOUFFER, P.C y BIERREGAARD, R. O. (2007). Recovery potential of understory bird communities in Amazonian rain forest fragments. Revista Brasileira de Ornitologia, 15: 219-229.

STOUFFER, P. C., BIERREGARD, R. O., STRONG, C.y LOVEJOY, T. E. (2006). Long-term landscape change and bird abundance in Amazonian rainforest fragments. Conservation Biology, 20: 1212-1223.

STRATFORD, J. A. y STOUFFER, P. C. (2001). Reduced feather growth rates of two common birds inhabiting
Central Amazonian Forest Fragments. Conservation Biology, 15: 721-728.

VEREA, C. y SOLORZANO, A. (1998). La avifauna del sotobosque de una selva decidua tropical en Venezuela. Ornitología Neotropical, 9: 161-176.

VILLARREAL, J. (2005). Evaluación ecológica rápida del Refugio de Vida Silvestre Bosque Diria. Informe final. INBio. Heredia, C.R.

YOUNG, B. E. (1999). La importancia de los fragmentos forestales en el mantenimiento de la diversidad ornitológica. Arlington. VA, EE.UU. 13 p.

YOUNG, B. E., DEROSIER, D. y POWELL, G. V. N. (1998). Diversity and conservation of understory birds in the Tilarán Mountains, Costa Rica. The Auk, 115(4): 998-1016.

ZANETTE, L., DOYLE, P. y TREMONT, S. M. (2000). Food shortage in small fragments: evidence from an area-sensitive passerine. Ecology, 81: 1654-1666. 